\title{
Frailes y campesinos en la guerra de separación de Cataluña (1640- 1660)*
}

\author{
Xavier Torres Sans \\ Universitat de Girona
}

RESUMEN: En este trabajo se analiza la participación del estamento eclesiástico en la guerra de separación de Cataluña de mediados del siglo XVII; en especial, la de muchos clérigos anónimos que se implicaron abiertamente en el conflicto. Para ello se han compilado una serie de testimonios extraídos de fuentes de diversa naturaleza: opúsculos y tratados coetáneos; documentos de ciertas órdenes religiosas; procesos incoados contra algunos predicadores. El argumento que se maneja es que dicha participación no sólo fue mucho más importante de lo que se supone, sino que tuvo que ver, a su vez, con el sesgo providencialista e incluso algo apocalíptico que tomó la contienda desde el comienzo. La colusión subsiguiente entre frailes y campesinos se ha explicado a menudo por la cercanía sociológica entre unos y otros. Sin embargo, en este artículo se subraya más bien el papel de la clerecía para otorgar un determinado sentido a los acontecimientos.

\section{Palabras Clave: Cataluña; Historia Moderna; guerra de separa- ción; Clero; Herejía.}

\section{Friars and peasants in the Catalan war of secession (1640-1660)}

ABSTRACT: This paper discusses the participation of the clergy in the Catalan war of secession in the mid-seventeenth century; in particular, the many anonymous clerics who openly involved in the conflict. To do so we have com-

* Este trabajo se inscribe en el proyecto de investigación de financiación pública del MICINN, HAR 2011-23151. Siglas utilizadas: Archivo de la Corona de Aragón (Barcelona) = ACA; Archivo Histórico Nacional (Madrid) $=$ AHN; Biblioteca de Cataluña (Barcelona) $=$ BC; Biblioteca de la Universitat de Barcelona (Barcelona) = BUB; Biblioteca Nacional de España $($ Madrid $)=$ BNE. 
piled a set of cases drawn from sources of different nature: contemporary pamphlets and treatises, documents of certain religious orders, and prosecutions against some preachers. The argument presented here is that such participation not only was much more important than has been assumed so far, but had to do, in turn, with the providential and some apocalyptic bias that the contest took from the start. The subsequent collusion between friars and peasants has often explained by sociological similarities between them. However, this paper stresses the role of the clergy to make sense in the events.

KEY WORDS: Catalonia; Early Modern History; war of secession; Clergy; Heresy.

La insurrección catalana de 1640 es bastante bien conocida en sus rasgos esenciales. Como es sabido, los excesos de los soldados de Felipe IV por tierras del Principado, así como una larga serie de enfrentamientos políticos y constitucionales entre las instituciones de la provincia (la Diputación y las Cortes) y los representantes de la Corona (desde el virrey de Cataluña hasta el valido, el conde-duque de Olivares), desencadenaron un levantamiento popular de considerable magnitud, así como la secesión catalana de la Monarquía Hispánica y la subsiguiente inserción de Cataluña en los dominios de los reyes de Francia durante casi dos décadas (1659). Todo ello en el marco, igualmente consabido, de la Guerra de los Treinta Años y su polarización entre las monarquías de España y Francia desde mediados de la década de $1630^{1}$.

No obstante, todavía no se ha prestado suficiente atención a la participación del estamento eclesiástico en la contienda. Se sabe, ciertamente, que algunos clérigos y teólogos catalanes alcanzaron notoriedad como propagandistas, ya fuera como autores de opúsculos de gran difusión, para legitimar «a los ojos del mundo» la causa del Principado; ya fuera mediante los correspondientes sermones institucionales, objeto, a su vez, de la pertinente impresión y divulgación ${ }^{2}$. El fraile agustino Gaspar Sala fue un prolífico -e incluso pionero - cultivador de ambos géneros, pues, además, de su célebre Proclamación católica (Barcelona, 1640), una obra patrocinada por el Consejo de Ciento barcelonés y que pudo ser «leída y recibida en gran parte del continente europeo», según K. Neumann, también dio a la imprenta el opúsculo intitulado Secrets públics (Barcelona, 1641), escrito en catalán y traducido a las lenguas castellana, portuguesa y francesa, así como un enfático ser-

1 Sendas monografías clásicas sobre el conflicto: ELLIOTT, 1977. SANABRE, 1956. Una síntesis reciente, TORRES, 2006.

2 GONZÁLEZ PEIRÓ, 1984; NEUMANN, 18/II (Barcelona, 1998): 373-381; TORRES y EXPÓSITO, 2012b: 129-150. 
món de San Jorge del año 1641, sobre la alianza entre Francia y Cataluña, entre otras obras suyas ${ }^{3}$. Desde luego, Sala no era un caso insólito. De un total de 24 textos propagandísticos publicados entre 1640 y 1646, todos ellos de autoría conocida y ciertamente significativos por una razón u otra, más de la mitad (catorce) eran obra de eclesiásticos; una proporción que se eleva considerablemente si no se toman en consideración los escritos del prolífico jurista Francisco Martí y Viladamor (con un total de seis títulos). Entre ellos, además del citado Sala, que se lleva indiscutiblemente la palma (con cinco opúsculos, y de los más difundidos), cabe citar a Antoni Marqués, otro agustino; Josep Font, sacristán de la iglesia parroquial de San Pedro de Ripoll; el franciscano Francisco Fornés, que llegó a ser «predicador y cronista de su Majestad Cristianísima»; el carmelita Josep de Jesús Maria, cronista asimismo del monarca francés y especializado en sermones sacro-políticos; y los teólogos Josep Sarroca y Josep Vallmajor ${ }^{4}$. Todo ello, sin olvidar el dictamen inicial, emitido por una junta de eclesiásticos del Principado a instancias de la Diputación catalana, que daba luz verde a la resistencia por tratarse, según se decía, de una guerra «justa» $\mathrm{o}$ 《defensiva» ${ }^{5}$. Ni, por supuesto, el conocido protagonismo en la contienda de Pau Claris, canónigo de la Seu de Urgel y presidente de la Generalitat en $1640^{6}$.

Sin embargo, en la guerra catalana de separación hubo también muchos otros eclesiásticos, anónimos o apenas conocidos, que contribuyeron asimismo a enardecer los ánimos de los insurrectos, alentando a los combatientes, bendiciendo sus acciones y sancionando, llegado el momento, el subsiguiente cambio de lealtad dinástica; ya fuera desde el púlpito, ya fuera - incluso- al pie de las trincheras. En este trabajo se trata precisamente de ellos, así como de sus actuaciones respectivas. Pues, tal como sucediera en muchas otras sublevaciones populares y provinciales coetáneas, los eclesiásticos — cabe recordar - siempre tuvieron un papel preponderante en la interpretación de los acontecimientos; razón por la cual pudieron contribuir a darles un sesgo no previsto de antemano ${ }^{7}$. Es más, en la Cataluña de 1640, los ardores de frailes y predicadores tuvieron bastante que ver con el cariz providencialista y algo

3 Sobre las traducciones de este género de escritos, véase TORRES, 1995a: 23, n.18.

4 Semblanza bio-bibliográfica de algunos de estos autores en SERRA, 1995: 5-22; y SIMON TARRÉS, 1999: 305-325.

5 Iustificació en Conciencia de haver pres lo Principat de Catalunya las Armas, per a resistir als soldats que de present la invadeixen y als altres que amenasan invadir-la, Barcelona, G. Nogués, 1640; Memorial Histórico Español, t. XXI, Madrid, Real Academia de la Historia, 1889, apéndice $\mathrm{n}^{\circ} 251$, págs. 218-239.

6 GARCÍA CÁRCEL, 1980; SIMON TARRÉS, 2008; y FONTANELLA, 2008.

7 Sobre la mediación de los eclesiásticos y su participación en los conflictos, no siempre suficientemente ponderada, véanse: BERCÉ, 1980: 79-83; MARQUES, 1989; y más recientemente, ARMSTRONG, 2004; y POLLMANN, 2011. 
apocalíptico que adoptara en ocasiones el levantamiento popular contra los tercios de Felipe IV, así como los primeros compases de la guerra catalana de separación.

\section{ECLESIÁSTICOS EN EL PÚLPITO}

Una de las conocidas «empresas» de Saavedra Fajardo, inscrita en su Idea de un príncipe político cristiano, una obra concebida en vísperas de las revueltas provinciales de la Monarquía Hispánica del año 1640, prevenía a los gobernantes sobre la influencia de los predicadores, esos «intérpretes entre Dios y los hombres», en el vulgo: «Con ellos —escribía este conocido polígrafo y diplomático español- es menester que esté muy advertido el príncipe, como con arcabuces por donde entran al pueblo los manantiales de la doctrina saludable o venenosa». En otras palabras, «Dellos depende la multitud, siendo instrumentos dispuestos a solevalla o a componella, como se experimenta [hoy] en las rebeliones de Cataluña y Portugal» ${ }^{8}$. La alusión a la revuelta catalana, ¿hasta qué punto puede considerarse exacta?

Desde luego, la Iglesia —o la clerecía — catalana no reaccionaron unánimemente ante los acontecimientos. En términos generales, puede decirse que los obispos de las diócesis del Principado se mantuvieron francamente leales a Felipe IV; mientras que los inquietos cabildos catedralicios, con bastantes cuentas pendientes con sus prelados, además de con el fisco real, se alinearon a menudo en el bando de las instituciones catalanas e incluso de la secesión dinástica ${ }^{9}$. Por su parte, las distintas órdenes religiosas siempre procuraron guardar las apariencias. Sus superiores, así como los capítulos provinciales de aquellos años, instaban a los suyos a mantenerse al margen de la contienda, pues, «grave yerro sería si a ninguno de los nuestros le cogiesen en la menor inadvertencia». De este modo, el general de la Compañía de Jesús, Muzio Vitelleschi, ordenaba que «de ninguna manera, ni de palabra ni por escrito, ni en púlpito o conversaciones particulares, se descuiden [los padres] en cosa que pueda ser de aprobación o fomento del fuego que se ha encendido», como pudiera ser, precisaba, «decir que al rey se le tiene la debida sujeción, pero que la oposición es con el mal gobierno de los ministros: estilo y frasi[s] con que han comenzado casi todas las rebeliones y tumultos que se saben» ${ }^{10}$. Por

8 SAAVEDRA FAJARDO, 1988: 380, Empresa 55 (Munich, 1640; 2a . ed., Milán, 1642).

9 Sobre este antagonismo secular, REGLÀ, 1956: 21-24. Un ejemplo de prelado catalán leal a la Corona, ROURERA, 1987. Excepciones (canónigos y abades en favor de Felipe IV) con el paso del tiempo o en según qué lugares, SANABRE, 1956: 278. Sobre la evolución del episcopado catalán a lo largo del conflicto, BUSQUETS, 1989: 61-75.

10 BATLLORI, 1971: 305. 
su parte, el capítulo provincial de la orden capuchina del año 1643 aprobaría una disposición según la cual, para evitar en adelante los «desórdenes» acaecidos hasta entonces, los miembros de la orden no podrían tratar de las «materias corrientes» desde el púlpito sin licencia de sus superiores, so pena de «suspensión del oficio de la predicación y otras penitencias acordes con la calidad del exceso». Todo ello ante el pasmo y el escándalo del visitador francés (y por entonces virrey de Cataluña) Pedro de Marca, quien no dudaría en convocar a todos padres los provinciales y superiores del Principado para instarles a «aconsejar y animar [a] los pueblos en sus sermones a guardar la fidelidad al Rey de Francia]»; a quien, además, había que citar por su nombre, a saber: «Rey Luis», y no rey «en abstracto» ${ }^{11}$.

Con todo, los aludidos no se dejaron intimidar; ni por unos ni por otros. Diez años después, cuando Barcelona volvía a estar en manos de Felipe IV pero la guerra con Francia aún no había concluido, un capítulo provincial de la orden capuchina reiteraba la prohibición de ocuparse de política, aunque por si acaso adoptaba un prudente o sinuoso accidentalismo dinástico, consistente en «hablar siempre a favor de España y de nuestro rey... sin menoscabo de Francia, así como los que viven en tierras [catalanas] sujetas [aún] a Francia, es bien que hablen a favor de Francia, sin menoscabo de España». Al año siguiente, toda cautela parecía poca, razón por la cual el capítulo provincial decretó, a su vez, que los frailes limosneros que fueran a la ciudad no inquirieran ni reportaran noticias sobre la guerra en curso $^{12}$.

Pero si las órdenes religiosas, como tales, «colaboraron activa y ardientemente al restablecimiento de la tranquilidad [pública]», tal como sugieren, a tenor de disposiciones semejantes, algunos autores, no es menos cierto que ni sus superiores ni las severas sanciones impuestas periódicamente no pudieron evitar la implicación en grados diversos - y a título individual, si se quierede un buen número de religiosos. Alguno de ellos, como el jesuita Jaume Puig, ya se había significado por su patriotismo (o «afición a Cataluña») en años anteriores (1626). Ahora, una vez consumado el divorcio con Felipe IV, se convirtió en uno de los propagandistas borbónicos más activo, llegando a ser nombrado predicador oficial del rey cristianísimo ${ }^{13}$. Lo mismo puede decirse del ya citado agustino Gaspar Sala, exrector del Colegio de San Gui-

11 SANABRE, 1956: 289. Marca se quejaba, a su vez, de que «los castellanos hacen seducir a los pueblos mediante la acción de los religiosos en las confesiones».

12 BASILI DE RUBÍ, 1977: 688, 797-798 y 807.

13 BATLLORI, 1971: 311-313. Entre sus panegíricos, véase su sermón fúnebre dedicado a Luis XIII, Sermó que predicà... en les Reals Exèquies que la... Ciutat de Barcelona celebrà... a la grata y bona memòria de Lluís XIII lo Just, Barcelona, J. Matevat, 1643; así como la Oración panegírica de los lirios reales de la Casa de Francia... en vida y muerte del Cristianísimo Rey Luis XIII llamado el Justo, Barcelona, J. Matevat, 1643. 
llermo de Barcelona (en 1630) y autor —además de la mencionada Proclamación católica - de una serie de escritos declaradamente pro-franceses. En una carta dirigida al padre provincial de los agustinos, fechada a finales del mes de mayo de 1640, Felipe IV se lamentaba ya de que «en ocasiones semejantes a la que sucede en la Provincia de Cataluña... suelen con celo indiscreto ocasionar en el pueblo los religiosos mayores inquietudes»; por ello, añadía imperativamente, «los que os pareciere que pueden causar este inconveniente... [será bien] mudéis a conventos [de] fuera de Cataluña ${ }^{14}$. Pero si hubo un colectivo religioso fuertemente implicado en el conflicto, éste parece haber sido la familia franciscana en general y la orden capuchina en particular. Así, en una carta fechada a principios del mes de agosto de 1640, el propio Felipe IV se quejaba de que «en Cataluña... casi todos los religiosos... obran con tanto escándalo... que no sólo se apartan de su instituto en sus sermones, pláticas y confesiones... sino que asisten a fortificaciones como si [se] previnieran para la guerra contra [los] infieles», precisando a continuación que «la de san Francisco ha procedido en esta parte con grande inconsideración, y así conviene reprimir y castigar mucho». Ciertamente, del capuchino fray Ermengol de Montblanc, definidor y custodio provincial del Rosellón, se sabía que no había dudado en denunciar en su día y en sus sermones los inclementes bombardeos (a mediados del mes de junio de 1640) de la villa de Perpiñán por parte del marqués Geri de la Rena, general de la artillería de Felipe IV. Unos pocos meses después, otro capuchino, fray Gervasio de Monistrol, sería designado maestro de obras en la fortificación de la montaña de Montjuïc, en vísperas del asedio de la capital catalana (a finales de enero de 1641). Quizá por estos y otros antecedentes, cuando cesó la contienda y el Principado - $\mathrm{O}$ su capital, Barcelona - regresaron a manos de Felipe IV, la represión subsiguiente se cebó ante todo en los miembros de dicha orden; con la complacencia, dicho sea de paso, si no instigación inclusive, de la orden dominicana, quizá la más fiel a Felipe IV a lo largo de todo el conflicto ${ }^{15}$.

Así, aunque la depuración del clero regular no conocería excepciones, tal como demostraron las visitas correspondientes a los distintos establecimientos del Principado, en el caso particular de los capuchinos se llegó a sopesar la erradicación entera de la orden en el Principado, dado que «casi todos ellos», se decía, «han cooperado contra el servicio de su Majestad», habiendo sido «gran parte en los aumentos y progresos de las armas francesas en Cata-

14 Memorial Histórico Español, t. XX, Madrid, Real Academia de la Historia, 1888, apéndice $\mathrm{n}^{\circ} 74$, pág. 307.

15 El dominico Francesc Crespí de Valldaura, obispo de Vich en 1654 y maestro provincial de la orden en Cataluña, fue uno de los principales perseguidores de capuchinos, BASILI DE RUBÍ, 1977: 533n. (carta de Felipe IV a fray J. B. Campania, ministro general de la orden franciscana), 660-669 y 800 (Crespí). 
luña», según aseguraba el Consejo de Aragón. Las reiteradas andanadas contra los capuchinos denunciaban que éstos habrían actuado «conmoviendo, con lo estrecho de la religión y de la devoción, que la tienen en la provincia, a toda hostilidad, predicando, exhortando y tomando las armas, [y] mostrándose a los pueblos [como] soldados de Dios», siempre según los ministros del Consejo de Aragón. Por su parte, don Juan José de Austria, el conquistador de Barcelona, escribía al generalato de la orden en términos idénticos: «En las alteraciones de estos años en Cataluña se han señalado generalmente los religiosos de vuestra orden con demostraciones muy contrarias a su profesión... y al servicio de Dios y mío, así en la predicación como en las confesiones, alentando los ánimos de aquellos naturales... a la inobediencia». La conclusión, pues, era que debería arrancarse tanta «cizaña» o «mala semilla» mediante los destierros oportunos. Apenas reconquistada Barcelona, en el mes de octubre de 1652, llamó poderosamente la atención el caso de fray Ángel de Barcelona, acusado de «dar ánimos a los desafectos» a Felipe IV, propagando el rumor de que las armas francesas volverían a no tardar. Pero todo parece indicar que, a pesar del carácter deliberadamente ejemplarizante de ciertas expulsiones, los incidentes de este género se repitieron - por lo menos fuera de Barcelona - hasta la conclusión de las paces definitivas con Francia. Así, en 1657, el propio Felipe IV escribía al virrey del Principado para denunciar, entre otros capuchinos, la persona de fray Ignacio de San Felío, que siempre «se mostró - dice - muy afecto... a Francia»; mientras que un año después de firmado el tratado de los Pirineos, todavía había capuchinos como fray Juan Evangelista de Sarriá que aprovechaban sus sermones dominicales para predicar, al parecer, contra Felipe IV ${ }^{16}$.

Así, según la denuncia presentada por el juez ordinario del vizcondado de Cabrera y Bas, testigo de los hechos, en el sermón que se predicó en la iglesia parroquial de la localidad de Blanes (La Selva) el domingo 12 de diciembre de 1660 el mencionado capuchino habría proferido «mil disparates, tratando a Su Majestad... de Rey inicuo y despechador (sic) de sus vasallos, y a sus ministros, de la misma manera, por lo cual faltó poco para que no se amotinase el lugar», como le explicaba el marqués de Mortara, por entonces virrey del Principado, al obispo de Gerona, a quien instaba a tomar rápidamente cartas en el asunto. El proceso eclesiástico subsiguiente puso de manifiesto, una vez más, las ambigüedades - o virtualidades - de un género aparentemente anodino, además de ciertamente ortodoxo, a saber: la paráfrasis bíblica. No en vano el sermón incriminado habría empezado como un simple comentario a la embajada que hicieran gobernantes y sacerdotes de Jerusalén, todos ellos temerosos de la venida del Mesías, a San Juan Bautista, para recabar informa-

16 BASILI DE RUBÍ, 1977: 795-796, 800-801, 821 y 824. 
ción sobre aquél (Jn I, 19). Ante su insistencia, el precursor les habría respondido que el Mesías sería «un rey justo, bueno y benigno», y que no toleraría «las iniquidades que ellos hacían, robando y pechando al pueblo [y] chupándole la sangre a los pobres», porque, además, «el rey que impone pechos y hace pagar contribuciones a sus vasallos, y que quiere vivir de la sangre de los pobres, es un rey injusto y inicuo». Para algunos de los fieles presentes era demasiado evidente que el capuchino estaba comparando a los fariseos y otros gobernantes jerosolimitanos con Felipe IV y algunos de sus ministros, quienes por entonces continuaban exigiendo contribuciones y alojamientos por toda Cataluña. Así, según otro de los asistentes al sermón, el capuchino habría dicho «muchas otras cosas aplicando el símile (sic) a los tiempos que corrían en este Principado».

Ciertamente, esa pudo ser una apreciación excesiva, pues, el predicador tuvo buen cuidado en desvincular al monarca — un rey "cristianísimo (sic), católico y piadoso» donde los hubiere - de cualquier exceso en materia fiscal o militar. La culpa, por el contrario, era de los ministros reales, pues, «aquella contribución y servicio que actualmente estaban exigiendo a los pueblos de Cataluña... no era sino para robar y vivir de la sangre de los pobres, pues, de otro modo, ¿cómo podrían [aquéllos] sustentar... esa multitud de criados [que tenían]?», así como el coche o carruaje en el que se paseaban, tan ufanos. Ya no quedaban, pues, buenos ministros; ya se había agotado aquel género de individuos «que miraban por el bien común». Otros feligreses fueron mucho más comedidos en sus apreciaciones. Algunos alegaron ser duros de oído, quizás para no incriminar al sacerdote. Otros se limitaron a decir que el predicador había deplorado tan solo los excesos ocurridos en los recientes alojamientos locales, pues, «por no poder pagar los pobres las tallas» que se les exigían, se les confiscaban inclusive las sábanas y las mantas de sus camastros. Por su parte, el acusado, que declaraba haber pasado más de 53 años (de los 71 que tenía por entonces) en el seno de la orden de los capuchinos, aseguraba tener la conciencia muy tranquila y haber actuado únicamente en nombre de la caridad, especialmente una vez comprobada la falta de piedad de los recolectores del impuesto, así como su injusto reparto, pues, «sólo los pobres soportan la carga de los trabajos de la villa»; una alusión no menos crítica a la exención fiscal de los estamentos privilegiados de la localidad. Finalmente, el asunto se zanjó con una pena leve ${ }^{17}$.

Las dificultades de este capuchino del lugar de Blanes no parecen haber sido un caso excepcional. Para entonces las denuncias (de cronología retrospectiva no siempre demasiado precisa) contra eclesiásticos ante los tribunales de la Inquisición estaban a la orden del día. Así, un rector de la parroquia de

17 ACA, Monacales Universidad, leg. $n^{\circ}$ 59, pliego nº 27, s/fol. 
Vilassar (en el actual Maresme) fue acusado de haber dicho en una ocasión a sus feligreses que si alguno «había estado en el campo de España» ya se podía dar por excomulgado. En la villa de Monistrol (Bages), un religioso de la orden de los agustinos (que tenía un colegio propio en dicha población) solía terminar sus sermones de Cuaresma solicitando a la concurrencia tres avemarías «para que Dios diese victoria al mariscal [francés] de la Mota [Motte] ${ }^{18}$ contra el Rey de España»; que era, añadía, «peor que Judas», razón por la cual concluía que «mejor era ser del Moro que del Rey de España». Años después, en pleno asedio de la ciudad de Barcelona (1651-1652), el vicario del lugar de Esparraguera (Bajo Llobregat) habría sentenciado que «pedir a Dios [que] diese las paces a los Reyes de España y Francia» era pecado mortal, dado que «sólo se le había de rogar [que] diese victoria a Francia». Acto seguido, habría añadido que «si España tomaba Barcelona, [él] no quería quedar su vasallo en Cataluña»; antes bien, «quería ser vasallo del Turco y vivir con el Moro [antes] que [serlo] del rey de España». De modo que lo mejor sería que «Cataluña se entregase al Turco [antes] que al rey de España». También se le habría oído decir públicamente que «cualquier persona lícitamente podía matar a cualquier español sin pecado»; y que era lícito asimismo «matar al Rey de España, y que cualquier persona que le matase y fuese a confesarse con él, [él] la absolvería», dado que, como sabía todo el mundo, «el rey de España era un hereje alumbrado...». Por las mismas fechas, un presbítero de Monistrol, «hablando de las guerras del Principado», habría asegurado que sólo se debía rogar a Dios por la victoria del rey de Francia, y que los que no lo hacían así «vivían en pecado mortal». En Barcelona, a su vez, los sermones que se escuchaban en sus iglesias tampoco habrían sido menos incendiarios; por lo menos, en la populosa basílica de Santa María del Mar. En uno de ellos se llegó a decir que «los castellanos no eran nuestros próximos». En otra ocasión, en plena celebración del oficio divino, un sacerdote, Diego Soler, beneficiado de la misma iglesia, habría interrumpido abruptamente la plegaria Da pacem, domine, aduciendo que «no eran éstos tiempos de pedir paz a Dios», sino que «se había de rezar la oración contra paganos y infieles, porque esto — añadía - [es lo que] eran los castellanos». Igual - al parecer - que muchos otros eclesiásticos del Principado, el beneficiado Soler también «primero se iría a vivir a Argel [antes] que no entre castellanos» ${ }^{19}$.

18 Por entonces, virrey de Cataluña (1643-1644).

19 AHN, Inquisición, Tribunal de Cataluña, Relación de causas de fe, lib. 734, ff. 192 (Diego Soler); 192v. (presbítero de Monistrol); 193v. (Santa Maria del Mar); f. 194v. (rector de Vilassar); ff. 253v.-257v. (vicario de Esparraguera); ff. 263v.-267v. (religioso agustino de Monistrol). 


\section{FRAILES EN LAS TRINCHERAS}

No resulta nada fácil - en aquel contexto de postguerra y delaciones previsiblemente interesadas - discernir la veracidad - e incluso representatividad - de tales acusaciones. Resulta sintomático, cuando menos, que el ya mencionado vicario de Esparraguera, que alentaba, según parece, el asesinato del monarca español, fuera tan sólo «gravemente advertido» y condenado a tres meses de arresto domiciliario. No menos reveladoras son, a su vez, las quejas, simétricas o en sentido contrario, del visitador-virrey Pedro de Marca, según el cual «los enemigos no solamente se sirven de las armas contra nosotros, sino sobre todo de la lengua de los sacerdotes, monjes y particularmente de los franciscanos, que claman abiertamente contra los franceses», además de persuadir a la gente de que «se encuentran en estado de pecado si no se someten al rey católico» ${ }^{20}$. Así, pues, ni todos los franciscanos conspiraron contra Felipe IV, tal como suponía el propio monarca, ni todos los religiosos del Principado se inclinaron por un mismo estandarte dinástico. De ahí, entonces, que levantaran sospechas por doquier.

Sea como fuere, el papel instigador de la clerecía catalana en la revuelta de 1640 se subraya en fuentes harto diversas. Para empezar, por supuesto, en la publicística patrocinada por la Corona. Así, según el anónimo autor de Aristarco, una réplica de la Proclamación católica de fray Gaspar Sala, los líderes de la rebelión catalana «solicitaron - dice- Predicadores que en sus Sermones moviesen la gente a la defensa de sus constituciones, [y] fingieron lágrimas en las Imágenes, y todo [ello] para levantar el Pueblo». Una imputación corroborada asimismo por otros propagandistas de Felipe IV, como el autor de Bozina pastoril y militar, un religioso no identificado que decía haber predicado algunos años antes en Cataluña y que ahora, a la vista de los acontecimientos, se acercaba nuevamente a sus ex-feligreses para exponerles el extravío del clero local: «Eclesiásticos sediciosos turbaron vuestra gloriosa paz. Clérigos y frailes fueron el escándalo», sentenciaba. Por su parte, algunos clérigos del Principado, como el deán y canónigo de Tortosa, Alejandro de Ros, también acusaban retrospectivamente a sus correligionarios de haber patrocinado la insurrección: «No puedo negar —escribía Ros- que se ha perdido el pueblo de Cataluña a persuasión de muchos eclesiásticos, que justificaron su sublevación, ya con papeles firmados... ya con sermones escandalosos». Con una prosa más retorcida, fray Pedro Moliner, un teólogo leridano al servicio de Felipe IV, también se lamentaba de lo mismo: «¿Qué estrago - se preguntaba - ha causado este férreo lustro en el estado Eclesiástico [que] rompió [los] términos de su clausura y el recato de su modestia, marchando

\footnotetext{
20 SANABRE, 1956: 289.
} 
con picas y mosquetes?». Y aún, «¿Cuántos [de ellos] se desaforaron [rondando] con gritería aseglarada [por] las calles de Barcelona?» ${ }^{21}$.

En el Principado, este género de imputaciones fueron corrientes desde el principio. A mediados del mes de mayo de 1640, en vísperas, pues, de la trágica jornada barcelonesa del Corpus de Sangre, el virrey conde de Santa Coloma ya se quejaba ante el monarca de los alarmantes sermones de ciertos clérigos locales. Unos meses más tarde, cuando la llegada de los ejércitos de Felipe IV era ya inminente, Juan de Garay, el comandante de los tercios acantonados en el Rosellón, se escandalizaba asimismo ante «la soltura del clero y [de los] religiosos de los conventos» locales, quienes habrían llegado «a lo último de la sedición y corrupción, porque en el confesionario y en el púlpito no tratan sino de soliviantar el pueblo» ${ }^{22}$. Algo después, los catalanes exiliados a raíz de los acontecimientos tampoco ahorraban invectivas contra los predicadores de su patria. Sus «soflamas» — decía uno de ellos — habrían contribuido a legitimar muchos asesinatos y saqueos; especialmente, «al proclamar que no se pecaba en degollar y hurtar a los castellanos, ministros del rey y afectos a su real servicio» ${ }^{23}$. Por su parte, Albert Tormé de Liori, otro partidario de Felipe IV, denunciaba la «protervia de algunos frailecillos más amotinados en escritos y púlpitos que los segadores en las plazas... exagerando siempre los sacrilegios de la soldada (sic)», además de urdir maquinaciones de todo género para engatusar a la gente corriente:

Los religiosos, que tan fácilmente encaminan al pueblo a su sentir... volvieron a interpelar en los púlpitos a los fieles con maravillas fabricadas en sus Ideas de señales vistas en la indignación de Dios contra [los] soldados, diciendo que Nuestra Señora del Roure, en el distrito de la villa de Figueras, sudó y lloró tres días [seguidos]... afirmando ser lícito a todo estado y deber contribuir seglares y religiosos con revelaciones y señales divinas... Por estos predicadores, [por el] crédito y autoridad que tienen en el pueblo, se siguió su doctrina, alistándose todos los estados. El confesor, el canónigo, el cura... en vez de cilicios visten mallas; [y] las horas que se han de ocupar en disciplina conventual, convierten en disciplina militar...24

21 Aristarco o Censura de la Proclamación Católica de los catalanes, Madrid, 1640, f. 16v., escrito atribuído a Francisco de Rioja, bibliotecario del conde-duque de Olivares; Bozina pastoril y militar que toca a recoger la antigua fe catalana, [Madrid, 1642], s/f.; ROS, Alexandro de, Cataluña desengañada, Nápoles, E. Longo, 1646, págs. 350-351; MOLINER, Pedro, Lágrimas del Ieremías catalán, s.l., s.n., [1644], s/f.

22 ELLIOTT, 1977: 394 y 429.

23 ZUDAIRE, 1964: 313n., que cita un manuscrito de un tal J. Viñals, intitulado Discurso octavo.

24 BNE, ms. 2371, f. 29v.30. Se trata, según parece, de una copia o traslado de los escritos de Alberto Tormé de Liori, que también pueden consultarse en BC, mss. 500 y 762, Miscelláneos históricos y políticos sobre la guerra de Cataluña desde el año 1639. 
No se trataba, al parecer, de imputaciones gratuitas. Los aludidos, por lo menos, nunca negaron en principio su implicación en los hechos. Por el contrario, el agustino Gaspar Sala, uno de los eclesiásticos más identificados con la causa catalana, no tenía ningún reparo en ensalzar la labor de aquellos predicadores locales que, a pesar de las amenazas de los ministros reales o - a veces - de sus propios superiores, no dudaban en denunciar «por los púlpitos, los sacrilegios cometidos contra el Santísimo Sacramento por los soldados de un Rey Católico, con sutilidad de conceptos y raridad (sic) de historias y lugares sacros», clamando, a su vez, «por la venganza de Dios Sacramentado» ${ }^{25}$.

Sin embargo, la implicación de la clerecía local en el conflicto no se redujo a pláticas y sermones. Llegado el momento, un buen número de eclesiásticos tampoco dudó en empuñar las armas, ya fuera en los prolegómenos de la revuelta popular, mezclados a veces con los airados segadores o jornaleros, ya fuera, más adelante, ante los ejércitos de Felipe IV, a fin de detener su avance por tierras del Principado. Los testimonios documentales de ello, aunque escasos y bastante dispersos geográficamente, son, con todo, suficientemente elocuentes. Así, el notario J. B. Sanz, cronista - resueltamente adverso- de las sucesivas revueltas populares acaecidas en la ciudad de Vich a lo largo del verano de 1640, señalaba, entre los cabecillas de los alborotadores, a un predicador local, prior del convento carmelitano de la ciudad; un personaje según Sanz- «no muy inteligente precisamente», aunque «muy amigo de los sediciosos, a quienes siempre acogía en su casa», y cuyos sermones, además, «en lugar de obviar motines, la verdad es que los renovaban», ya fuera por incompetencia, como pensaban algunos, o más bien adrede, como creía firmemente Sanz. Más adelante, este mismo cronista local consignaba la captura por parte de las autoridades de un «capellán de la Segarra que llevaba bastante tiempo en Vich» y que - siempre según Sanz- no era precisamente un dechado de virtudes: «indigno del estado sacerdotal», tenía atemorizados a sus superiores, además de alentar en su día el asalto e incendio de la casa del conseller en cap o primer magistrado de la ciudad, Antoni Illa, quien no salió con vida de aquella acometida. Por aquellas mismas fechas, el consejo de la ciudad solicitaba asimismo la captura de otro sacerdote, un tal Segimon Rosic, cuyos oficios divinos, se argüía, no podían resultar más «perjudiciales para la quietud y la paz pública de esta ciudad».

A tenor de estas y otras fuentes, el núcleo de la revuelta vicense se localizaba en los arrabales de la ciudad, especialmente en el de San Pedro, ubicado en el sector meridional de la urbe, y cuyos habitantes, es decir, inmigrantes

25 SALA, Gaspar, Epitome de los principios y progresos de las guerras del Principado de Cataluña en los años 1640-1641 y señalada victoria de Montjuyque, Barcelona, P. Lacavalleria, 1641, s/f. 
franceses y pequeños artesanos y jornaleros del país, azuzados por capitostes como Joan Francesc Moragull, el denominado Gabacho Ripoll o un tal Oliver, alias el Cristo Santo (lo Sant Crist), «siempre fueron - según Sanzcaudillos y declarados enemigos de la ciudad y de la quietud pública». De hecho, el enfrentamiento entre la ciudad - las fuerzas vivas y algunas de sus milicias gremiales - y el arrabal rebelde por antonomasia - las gentes de San Pedro - se prolongó durante más de tres meses, desde fines de mayo hasta los últimos días de agosto, con profusión de barricadas, emboscadas y tiroteos, así como de treguas y parlamentos periódicos, con sus respectivos emisarios o plenipotenciarios y los subsiguientes pliegos de condiciones, como si de dos ejércitos enemigos se tratara. Todo ello en vano. Después de unos meses de calma más aparente que real, la insurrección popular rebrotó nuevamente en vísperas de Navidad, a raíz de la caída de la ciudad de Tarragona en manos de los ejércitos de Felipe IV. Y una vez más, algunos eclesiásticos no dudaron en hacer causa común con las gentes de los arrabales - el de San Pedro a la cabeza, como siempre- e incluso con aquellos forasteros e incendiarios que merodeaban amenazadoramente por los alrededores de la ciudad, a la espera de su oportunidad. Este fuera el caso del prior del convento del Carmen, fray Mateu Grau i Astor, «un hombre - siempre según Sanz- de mucha presunción y pocas luces... que los amparaba... y que con sus prédicas los alentaba, diciendo que en la ciudad de Vich había traidores» y que el «enemigo», es decir, las tropas de Felipe IV, amenazaba también el «corazón de la provincia», o sea, la ciudad de Barcelona. El consejo municipal vicense tampoco tenía una mejor opinión de fray Mateu, razón por la cual solicitaba al provincial de la orden su inmediato destierro o traslado, dado que «en diversas ocasiones, con sus acciones... ha dado pie a inquietudes entre la gente de esta ciudad» ${ }^{26}$.

El protagonismo de monjes y frailes no habría sido menos visible en la lucha contra los tercios del monarca, especialmente a raíz de su masiva entrada en el Principado, a fines de noviembre de 1640. En el lugar de Cambrils, una localidad del Campo de Tarragona donde las tropas pasaron a cuchillo a todos sus defensores, muchos de los que plantaron cara o batalla fueron, según uno de los militares implicados en la matanza ulterior, «religiosos, así Franciscos (sic) como Carmelitas Descalzos, Bernardos y Benitos y Clérigos, y éstos eran los que más daño hicieron y valor mostraron, animando a los seglares». Unos meses después, la clerecía seguía aún en pie de guerra. Así, en el lugar de Martorell, cerca de Barcelona, las tropas, según otro testimonio de los hechos, encontraron asimismo «mucha cantidad de gente y de frailes francis$\cos$ (sic), que, levantadas las túnicas, pelearon como leones, en que concurrie-

26 SIMON TARRÉS , 2003a: 139, 142 y 159. Sobre los sucesos vicenses del año 1640, TORRES SANS, 1995b: 111-122. 
ron muchos campesinos» ${ }^{27}$. Estos y otros casos semejantes no debieran suscitar perplejidad. En una ciudad como Barcelona, pero también en otras partes, los eclesiásticos, cabe recordar, formaban parte del sistema defensivo urbano: por lo menos, en casos de emergencia ${ }^{28}$. Por ello, en uno de sus escritos, el agustino Gaspar Sala ensalzaba las compañías de religiosos barceloneses levantadas a raíz de la caída de Tarragona, a fines de diciembre de 1640, así como sus servicios prestados, que fueron ciertamente de todo tipo:

Desde la retirada de Tarragona, los Eclesiásticos y Religiosos de todas Órdenes... por su turno acudían a la guarda de la ciudad de Barcelona. Pero particularmente desde este día se mostraron más cuidadosos y fervorosos, acudiendo del altar y coro a los portales y muros; andando cargados de breviarios y mosquetes, de rosarios y cuerda [para los mosquetes], de armas espirituales y materiales... acudiendo unos y otros a sus puestos señalados» ${ }^{29}$.

Un memorialista local, el zurrador Miquel Parets, nos ha legado una imagen memorable de este género de religiosos, que se acercaban a las trincheras con un crucifijo en una mano y un pedreñal en la otra, azuzando a los defensores y asegurándoles que aquella guerra o resistencia era «justa» ${ }^{30}$. Por su parte, el sacristán de San Pedro de Ripoll, Josep Font, hombre ya mayor y aquejado — según dice - de una cruel enfermedad, no se recataba en afirmar que en semejantes circunstancias, es decir, cuando peligraran o estuvieran a punto de «perderse la República», la patria y el bien común, los eclesiásticos, a pesar de la existencia de cánones inicialmente en sentido contrario, tenían la obligación de alzarse en armas: razón por la cual, sentenciaba, a continuación, «pueden y deben los clérigos y religiosos catalanes, tomar las armas contra las castellanas en defensa de su patria». Una apreciación que también compartía el doctor en teología Josep Vallmajor, máxime si se tenía en cuenta —añadía-

27 ZUDAIRE, 1964: 376n.

28 DURAN SANPERE, 1973, vol. II: 109-123; y SERRA, 5 (Barcelona, 2001): 221n. Los eclesiásticos no figuraban en las ordenanzas militares urbanas de 1626 (Orde militar dels puestos als quals las compañias y altras personas de la ciutat de Barcelona han de acudir en temps de guerra o rebatos, Barcelona, J. Margarit, 1626), pero sí en las de 1646 (Repartiment de la gent de guerra dels quatre tercios de la ciutat de Barcelona y de las parrochies y monastirs... y llochs ahont han de acudir y defensar en cas de rebato o invasió de enemichs, Barcelona, P. J. Dexeu, 1646). Véase la distribución de los efectivos, sacerdotes y canónigos incluidos, sobre el terreno, es decir, en las murallas y baluartes de la Barcelona del año 1646, en SOBREQUÉS, 1992, vol. IV: 271.

29 SALA, Epitome, op. cit., s/f.

30 PARETS, Miquel, De molts sucsesos que han sucseÿt dins Barselona y en molts altros llochs de Catalunya dignes de memòria, $\mathrm{BUB}, \mathrm{ms} .224, \mathrm{f} .74 \mathrm{v}$. 
que Cataluña estaba «invadida de sacrílegos» —o soldados del rey— que no cesaban de saquear e incendiar iglesias ${ }^{31}$.

\section{LA CONFESIONALIZACIÓN DE LA GUERRA}

Así, pues, aun cuando muchas congregaciones eclesiásticas trataran de mantenerse por encima del conflicto, nada pudo evitar que la participación del clero, tanto regular como secular, en la contienda alcanzara cotas bastante elevadas, tanto por acción como por omisión, y ya fuera desde el púlpito, su ámbito de actuación natural, o el confesionario inclusive, tal como sugerían algunos informes del Consejo de Aragón; ya fuera manu militari, es decir, como un combatiente más. Se han aducido diversas razones para explicar un grado de implicación semejante. Por una parte, se dice, algunos exponentes - $\mathrm{o}$ en muchos casos, el grueso- del clero regular local apenas se diferenciaban, por su status material e incluso por su procedencia o extracción social, de sus convecinos; de modo que su adhesión a la insurrección del campo catalán bien pudo ser tan espontánea como inevitable ${ }^{32}$. Ciertamente, aunque no sea posible trazar - en Cataluña ni en otras latitudes - una divisoria demasiado nítida entre órdenes nobiliarias y órdenes populares, no cabe duda - argüía A. Domínguez Ortiz, en su clásico estudio sobre el estamento eclesiástico en la España moderna- que algunas de ellas, «por su reclutamiento, cultura, ocupaciones y medios de vida, estaban más en contacto con el pueblo que otras»; y que ello, añadía, «tuvo en ciertos momentos consecuencias de carácter social y hasta político» ${ }^{33}$. En el caso de la denominada Cataluña Vieja, tierra de masías, asentamiento disperso y régimen de heredero único, además de epicentro de la revuelta popular de 1640, la peculiar simbiosis entre el mas y la iglesia —o mejor, entre las masías, las obrerías parroquiales y la rectorías de los alrededores, ocupadas a menudo por vástagos salidos de las primeraspudo incrementar, si cabe, la sintonía entre el clero secular y los campesinos acomodados, no menos airados e insurrectos, cabe recordar, que los segadores o jornaleros en los inicios del levantamiento popular contra los tercios ${ }^{34}$.

31 FONT, Iusepe, Catalana Iusticia contra las Castellanas Armas, Barcelona, J. Mathevat, 1641, p. 59; VALLMAJOR, Joseph., Frenum Detrahentium. Fre ab lo qual se tapa la boca als detractors que han posada la llengua en las personas eclesiásticas de Catalunya, per haver presas las armas, resistint y defensant-se dels excessos dels soldats y exèrcit del rei de Castella, Barcelona, J. Matevat, 1643.

32 REGLÀ, 1956: 23.

33 DOMÍNGUEZ ORTIZ, 1970: 83. En la misma senda, MARTÍNEZ RUIZ, 2004: 191197; y BARRIO GOZALO, 2010: 231 y 354.

34 SALES, 1989: 211-216. Sobre el reclutamiento del clero secular local, véase PUIGVERT, 2000: 70-76. 
Por otra parte, en 1640 coleaban aún en Cataluña las secuelas de la implantación de la décima y de la revuelta eclesiástica subsiguiente. Esta nueva imposición de la Corona sobre los bienes de la Iglesia sublevaría en principio a los (comparativamente ricos) cabildos del país, una vez más enfrentados con sus obispos respectivos. Sin embargo, no tardaría en arrastrar, a su vez, a ciertos miembros de las órdenes religiosas locales, siquiera fuese en nombre de las denominadas «libertades de la Iglesia» y su defensa frente al poder secular, tal como se vio en la ciudad y en la catedral de Vic a mediados del año 1634 , cuando se oyeron también algunos sermones incendiarios contra el monarca gobernante. Si un domingo de principios del mes de julio, un dominico, predicando en la catedral de la ciudad, arremetió «muy aguda y libremente en contra de Su Majestad... diciendo que era una cosa muy grave el obligar a pagar a los eclesiásticos sin mostrarles la [pertinente] bula de Su Santidad... porque esto iba contra la razón y la justicia», al poco, un capuchino, fray Atanasio, redoblaba los ataques en la misma sede y se despachaba «mucho más y más libremente que el anterior, diciendo [además] que le importaba un rábano si lo desterraban», tal como le ocurriera a su predecesor ${ }^{35}$.

Sin embargo, al lado de estos factores de corte sociológico, la elevada movilización de los eclesiásticos catalanes en la guerra de Separación del Principado también puede ser interpretada como una secuela de la guerra contra Francia declarada en 1635. Como se sabe, esta nueva conflagración dinástica e internacional se planteó, del lado español, como una guerra de religión, y más exactamente aún, como un episodio más de la interminable lucha, acaudillada siempre por la Casa de Austria, contra la herejía, ahora encarnada por la corona francesa y sus aliados tradicionales - el turco-o recientes - como suecos y daneses, además de holandeses, en el marco de la Guerra de los Treinta Años $^{36}$. De ahí, pues, la necesidad de una movilización general, tal como argüían algunos publicistas eclesiásticos: «Tiene su Santidad en España - escribía el fraile agustino Juan de Herrera - al Católico Rey don Felipe... y a toda la casa de Austria... para defender a fuego y sangre todas las causas de la fe y religión cristiana, y particularmente del santísimo sacramento». Para una empresa semejante nadie podía dudar que Felipe IV pondría todos los medios a su alcance, es decir, su «vida, mujer, hijos, reinos y vasallos y a todos los españoles, que saldrán a defender a fuego y sangre al verdadero Dios.... ${ }^{37}$. De esta masiva movilización de recursos o efectivos no se excluía, por supuesto, al estamento eclesiástico. Tal como concluía el canónigo pre-

35 TORRES SANS, 2012a, vol. II: 895.

36 JOVER, 1949; DENTONE, 2000. Véase, además, CHAPARRO, 2012.

37 JUAN DE HERRERA, Querella y pleyto criminal contra los delictos enormes que Xatillon, capitán general del Christianíssimo señor Rey de Francia y su exército cometieron en Trillimon (sic), BNE, ms. 2366, ff. 440-464v. (cita, f. 447). 
mostratense Ambrosio Bautista, autor de un lóbrego «discurso» sobre las «miserias de la vida» y las «calamidades de la religión católica», ante un panorama semejante, «ni aún el sacerdote puede contenerse la defensa dentro de lo permitido, cuando es la ocasión tan violenta y necesaria. Mira entre las fieras - añadía, desolado - a IESUS, manso Cordero en el pesebre.... $\gg^{38}$. No otra cosa pensaban muchos eclesiásticos catalanes a la vista de los desmanes de los tercios en algunas iglesias del Principado. La guerra catalana de Separación empezaría también como una guerra de religión o - cuando menoscomo un combate contra la herejía. De este modo, la guerra contra Francia habría activado a los clérigos en todas partes. Y éstos, a su vez, no habrían vacilado en movilizar a sus feligresías respectivas mediante sendos y persistentes llamados a la acción. Sólo era cuestión de tiempo, pues, que esta nutrida y ardorosa movilización del estamento eclesiástico se trocara en Cataluña en rebelión abierta.

Por último, tampoco debe olvidarse que algunos establecimientos eclesiásticos podían llegar a ser auténticos semilleros de ideas subversivas, por lo menos en ciertas latitudes: Giordano Bruno y Tommaso Campanella salieron - subrayaba R. Villari- del convento napolitano de San Domenico Maggio$\mathrm{re}^{39}$. Aunque tal vez no haya que ir o llegar tan lejos, pues, para ejercer su influencia, los eclesiásticos, por lo general, no necesitaban alcanzar grandes cotas de heterodoxia: simplemente, por su función en la sociedad estamental del momento, así como por su formación, muchos de ellos estaban especialmente capacitados (e incluso legitimados) para otorgar en un momento dado un cierto sentido a los acontecimientos, propiciando de paso un determinado curso de acción ${ }^{40}$. Eso es algo que supieron hacer francamente bien - como se sabe- algunos reputados teólogos catalanes desde el principio, es decir, en la crítica coyuntura del año 1640. Este fue el caso del varias veces mencionado Gaspar Sala y aún de otros conocidos propagandistas del Principado. Sin embargo, todo parece indicar que un buen número de predicadores locales, mucho menos conocidos o apenas documentados, no les fueron a la zaga.

Ciertamente, en 1640, los campesinos y lugareños ultrajados por los tercios no precisaban de ninguna sanción eclesiástica particular para alzarse en armas. Si, por una parte, nunca dejaron de apelar a aquellas constituciones catalanas que regulaban -o limitaban - las obligaciones de la población en materia militar, por otra, la tradicional organización vecinal de defensa —el somatén local - fue suficiente para movilizar un pueblo tras otro en la lucha

38 BAUTISTA, Ambrosio: Breve discurso de las miserias de la vida humana y calamidades de la religión católica, Madrid, Imprenta Real, 1635, proemio «Al verdadero católico».

39 VILLARI, 1979: 80-84.

40 Sobre el papel del liderazgo clerical en la respuesta popular ante los acontecimientos, POLLMANN, 2011: 198. 
contra los soldados. Sin embargo, la legitimación religiosa de sus actuaciones fue relevante en un doble sentido, por lo menos. Ante todo, porque el fiel de la balanza podía haberse inclinado fácilmente del otro lado, ayudando a justificar las exacciones militares en curso o apaciguando cuando menos los ánimos más exaltados. De hecho, en la jornada barcelonesa del Corpus de Sangre, el 7 de junio de 1640, la violencia de los segadores sólo se contuvo cuando se toparon con una solemne procesión de autoridades civiles y religiosas, encabezada por el obispo de Barcelona y secundada por algunos frailes del cercano convento de san Francisco, a quienes se vio blandiendo una custodia y un gran crucifijo ${ }^{41}$. En Vich, otra urbe fuertemente zarandeada por las irrupciones de forasteros armados y de la gente de los arrabales, también se procedió a una demostración semejante, aunque en este caso el protagonismo recayera ante todo en algunos miembros de otras órdenes religiosas. En la aciaga jornada del 22 de mayo, que acabó con la muerte del consejero Antoni Illa, una improvisada procesión de frailes capuchinos y trinitarios descalzos, además de algunos jesuitas, todos ellos parapetados tras el crucifijo y la custodia de rigor, y entonando cánticos (el miserere) y jaculatorias (jmisericordia $_{i}$ ), consiguieron salvar in extremis de las llamas las viviendas y las pertenencias de otras autoridades locales ${ }^{42}$. Así, pues, la religión, en realidad, era un arma de doble filo: tanto podía neutralizar como azuzar la revuelta. De ahí, entonces, la importancia del aval eclesiástico a las actuaciones de los somatenes rurales durante la primavera del año 1640, rubricado — como se verá más adelante - con la solemne excomunión de los tercios de Leonardo Moles por parte del obispo de Gerona, a raíz del incendio de la iglesia de Riudarenes.

A su vez, la sanción religiosa de la revuelta popular fue también decisiva en otro sentido, pues, con su peculiar lectura de los acontecimientos, rápidamente asimilados a una suerte de lucha épica contra la herejía, los eclesiásticos reforzaron un determinado curso de acción y contribuyeron a encauzar aquéllos en una dirección no necesariamente prevista de antemano. Fue así como la tesis catalana de un «alboroto católico» 43 acabó por imponerse a cualquier otra visión o narrativa del conflicto, al socaire de la exaltada atmósfera providencialista que se arrastraba desde la declaración de hostilidades entre Francia - la potencia «herética»— y España — todo lo contrario, en suma- en el año 1635.

\footnotetext{
41 Compilación de testimonios en CATALÀ ROCA, 1988: 343-346.

42 SIMON, 2003: 129-130.

43 SIMON TARRÉS, 23/II (Barcelona, 2003): 123-146.
} 


\section{Providencialismo}

Desde luego, la agitación eclesiástica y la alianza entre clérigos locales e insurrectos rurales empezó mucho antes del comienzo de la guerra de Separación del Principado, que puede fecharse hacia finales del año 1640. Es más, a tenor de ciertos testimonios, tampoco se puede excluir la hipótesis de que la campiña catalana, enardecida por la reciente y sangrienta reconquista de la fortaleza de Salses (Rosellón), en manos de los franceses desde el verano anterior $^{44}$, así como por el eco providencialista de la (ya mencionada) publicística española de la guerra contra Francia, no haya conocido una verdadera oleada escatológica desde - por lo menos - la primavera del año 1640, cuando los conflictos entre soldados y lugareños se agudizaron, llegando al súmmum a raíz del asalto e incendio de algunas iglesias locales, donde los parroquianos trataban de preservar sus enseres y sus reservas de grano ${ }^{45}$. Este género de excesos, protagonizados por las huestes de un rey que se decía católico por encima de todo, tal como se subrayaba punzantemente en algunos opúsculos y memoriales del momento, ayudaron a propagar la imagen de unos tercios en connivencia con la herejía, si no herejes en sí, e incluso alimentaron presagios y admoniciones de carácter apocalíptico. Así, a mediados del mes de febrero, en un domingo de Carnaval, los consejeros de Barcelona se encontraron un papel estampado, firmado por un autodenominado «Verdadero Ángel de Luz» (Verdader Àngel de Llum), en el que se recriminaba, «de parte del Señor», la pasividad de las autoridades urbanas ante los soldadosherejes y sus desmanes; razón por la cual, vaticinaba aquel «ángel del Señor», si no se reaccionaba prontamente, sólo cabía esperar «la total ruina de todo el Principado»; si no de España entera, pues, «España peligra cuando Cataluña fluctúa». Cuando los atribulados consejeros leían estas líneas, el mismo texto o impreso circulaba ya ampliamente por las calles y plazas de la ciudad.

Este singular escrito, que se conoce únicamente por un par de copias manuscritas, resulta ciertamente algo desconcertante. Y no sólo por su enigmática autoría. Más adelante, ésta sería reivindicada por el jurista y publicista Francisco Martí Viladamor; una atribución, cabe señalar, bastante improbable, a tenor del contenido e incluso del estilo del escrito, por no mencionar su

44 La fortaleza, conquistada por los franceses en julio de 1639 , fue finalmente recobrada a principios de 1640 por un heteróclito contingente de combatientes, que incluía desde soldados de los tercios, levas y somatenes locales (las primeras, a cargo de la Diputación) y el grueso de la nobleza catalana, aunque al precio, según algunas fuentes, de la muerte de «miles de hombres» y de casi la mitad de la nobleza que hizo acto de presencia en el sitio (unos 450 caballeros), especialmente por enfermedad o contagio de peste; véase, SERRA, 1988, II: 7-28. Para más detalles, TORRES, 2006: 59-65.

45 PUIGVERT, 1991: 102-103. 
sintaxis, más bien precaria (si no fuera, en realidad, impericia del copista). Sea como fuere, lo más chocante es ante todo la argumentación expuesta, pues, en este caso, los enemigos a erradicar no son precisamente los soldados de los tercios, que no aparecen por ningún lado, sino más bien los inmigrantes franceses establecidos en el Principado, cuya lealtad, más que dudosa, contaminaba fácilmente a los naturales, induciéndoles a la más grande de las «inobediencias» (es decir, cabe pensar, a la herejía). Así, pues, según este anónimo «Ángel de luz», la raíz de todos los males era que la mayoría de los habitantes de Cataluña eran franceses o tenían «algo de sangre francesa». Por esta razón, había esa «infinidad de nubes [que] ocultaban el más grande de los soles». A continuación, el autor se demoraba en la descripción del desvencijado estado moral del Principado catalán, a saber: «la veneración grande de los templos, maculada; la Iglesia, afligida; la devoción, menospreciada [y] los vicios, multiplicados»; especialmente, la lujuria, la murmuración lujuriosa y la «glotonería virtuosa» (sic). A este género de desdichas debía añadirse aún - y algo más prosaicamente - la ruina de las haciendas locales, el «sojuzgamiento» de la nobleza o la «pérdida» de las libertades: señales no menos premonitorias del inminente cataclismo final. Por todo ello, la ciudad de Barcelona, igual como Cataluña entera, tenían que mostrar su arrepentimiento. Esta era, efectivamente, la única solución: «Penitencia pública, johi Barcelona; penitencia pública». Una recomendación que se hacía extensiva al Principado entero: «Cataluña. Penitencia [y] penitencia; [este es] el único remedio a tantos males». En suma, un texto algo equívoco, más propio, en algunos pasajes por lo menos, del contexto de la guerra contra Francia iniciada el año 1635 que no de la inminente revuelta catalana de 1640, aun cuando a la postre (¿podría tratarse de un texto reciclado?) se aluda a las maltrechas libertades del país. Sea como fuere, si la fecha del manuscrito (un 19 de febrero de 1640) resultara correcta $u$ original (e incluso si el texto hubiera sido concebido anteriormente, en plena ocupación francesa de la fortaleza de Salsas, como parece lo más probable), no cabe duda de que ya por aquel entonces alguien agitaba las procelosas aguas de la guerra santa: «El Señor está airado, aplaca [Barcelona] tanta ira... arma a tus particulares, no te desarmes», concluía el «enviado de lo Alto» ${ }^{46}$.

En los meses siguientes, los altercados entre soldados y naturales fueron en aumento, además de incrementar sensiblemente su radio de acción, que ahora iba desde las comarcas del condado de Rosellón hacia las proximidades de la ciudad de Gerona o más allá aún. Así, en el lugar de Santa Coloma de

46 BC, ms. 503, ff. 33-35; BC, Colección Bonsoms, nº 6138 (ms.). La autoatribución retrospectiva, en MARTí VILADAMOR, Francisco, Avisos del castellano fingido al insigne Principado de Cataluña. En 26 de febrero del año 1641 (sic). Por mandato de los Señores Deputados del General de Cataluña, Barcelona, G. Nogués, [1641]. 
Farners, a finales del mes de abril, hubo una auténtica batalla campal entre los vecinos, encabezados, según parece, por un clérigo local, Francesc Montagut, y los soldados del tercio de Juan de Arce, siempre a cuenta de los alojamientos militares. No era un incidente aislado o insólito, pero en este caso el desenlace fue ciertamente desolador: los soldados pegaron fuego a un cierto número de casas del lugar, pero en la refriega también perecieron a manos de la multitud el alguacil real Miquel Joan de Montrodon, autor a su vez de la muerte de un lugareño, y algunos de sus lacayos. Acto seguido, los somatenes de la comarca asediaron a los efectivos del tercio de Leonardo Moles, quien se vio obligado a emprender una atropellada retirada, no sin antes saquear tanto el pueblo como la iglesia de Riudarenes. Según se refería en la correspondiente relación impresa de los hechos, los soldados habrían volado las puertas de la iglesia e incluso tiroteado a los vecinos desde lo alto del campanario. De paso, se habrían llevado «todos los vasos sagrados», es decir, cuatro cálices y un incensario de plata, una custodia «dorada» y una gran cruz procesional, entre otras valiosas piezas del ajuar de la iglesia ${ }^{47}$. Sin embargo, según este mismo género de fuentes, dos capuchinos gerundenses pudieron salvar milagrosamente la custodia e incluso las formas sagradas (que aparecieron incólumes, aunque algo ennegrecidas): «O corazón humano — clamaban los frailes capuchinos-, cómo no revientas de dolor viendo así tratado a tu Dios quemado en su misma casa.... ${ }^{48}$.

Estos y otros desmanes similares en diversos lugares del Ampurdán acabaron con la solemne - e insólita - excomunión de los tercios protagonistas por parte del obispo de Gerona, Gregorio Parcero, lo cual — dicho sea de paso- dio alas tanto a la revuelta popular o espontánea contra los soldados como a la (llamémosle) insurrección católica que algunos auguraban o azuzaban desde hacía tiempo. No había para menos: «Esto, señor — escribía, indignado, el obispo gerundense al virrey del Principado-, ha sucedido en España, donde se conserva la pureza mayor de nuestra fe, y por soldados que militan debajo de las banderas católicas de su Majestad» ${ }^{49}$. El subsiguiente ceremonial de excomunicación — pena contra los herejes por excelencia - fue sobrecoge-

47 ETTINGHAUSEN, 1993, I: 73-83, opúsculo intitulado — significativamente- Senyor Déu Meu Iesuchrist, Iudique Vostra Magestat sa causa, sin pie de edición. Otro ejemplar en BNE, VE/211-87.

48 Caso horrendo y portentoso digno de llorar, haora (sic) sucedido, en BC, Ms. 503, ff. 19-26 (otra copia manuscrita en BC, Folletos Bonsoms, no 6136. Véase también, Al Principado de Cataluña, en BC, Ms. 503, ff. 41-48v.

49 Gregorio Parcero, un benedictino de origen gallego (Tui, a. 1570 - Tortosa, 1663), fue obispo de Gerona desde 1633 a 1656. Durante la guerra de Separación se negó a prestar juramento al rey de Francia, razón por la cual las autoridades franco-catalanas optaron por desterrarlo a principios del año 1643. Regresó a la diócesis gerundense diez años después; véase BUSQUETS DALMAU, 1994, I: 544-557. 
dor, como de costumbre. En la mañana del 13 de mayo las campanas de la catedral doblaban sin cesar. Dentro del templo, los bancos se habían recubierto de ropajes negros para la ocasión, y las autoridades municipales, así como un buen número de caballeros de la ciudad, ocupaban las primeras filas, todos ellos vestidos asimismo de luto riguroso. Poco después, en medio de un gran silencio, los congregados pudieron escuchar cómo el obispo Parcero declaraba por «excomunicados, anatemizados y malditos» a los soldados del tercio de Leonardo Moles, los autores de la quema de Riudarenes. El prelado y los canónigos gerundenses lanzaron al suelo y pisotearon trece candelas encendidas. Luego se acercaron procesionalmente hasta la puerta principal de la catedral, desde donde arrojaron escaleras abajo un total asimismo de trece piedras; todo ello mientras no paraban de entonar los primeros versículos del salmo 109: «Deus, laudem meam en tacueris / Quia os peccatoris et os dolosi siper me apertum est» («Dios, alabanza mía, no calles / Porque la boca del impío y del doloso se abre contra mí»). Una forma, en suma, de denunciar a los sacrílegos e impetrar - por una vía u otra - la correspondiente venganza divina. Sin duda, aquellos campesinos y vecinos de los alrededores que llevaban semanas peleando por su cuenta y riesgo contra los tercios no podían salir más reconfortados del evento ni menos autorizados para proseguir con su cruzada particular ${ }^{50}$.

\section{A MOdO DE CONCLUSIÓN}

Así, pues, en los meses de verano de 1640, un buen número de clérigos y segadores o insurrectos rurales parecen haber actuado al unísono o cuando menos bajo un mismo impulso o afán. Ciertamente, no todos los campesinos y vecinos ultrajados por los tercios, entonces o a lo largo de la década de 1630, siguieron esta senda. Algunas familias del lugar de Garriguella, en el Ampurdán, optaron en su momento por denunciar los hechos ante notario; mientras que en otras localidades las autoridades municipales solicitaron el amparo formal de la Diputación, una vez desechada, por parcial o interesada, la mediación de la Real Audiencia ${ }^{51}$. Por su parte, Joan Guàrdia, un enfiteuta medio de la región del Collsacabra (en las cercanías del llano de Vich) que llevaba guerreando contra los soldados desde el año 1634, consigna en su diario tanto la abrasión del «Santísimo Sacramento» en el lugar de Riudarenes

50 BUSQUETS DALMAU, 1994, I: 401-402 (la versión del salmo ha sido extraída de la edición de la Biblioteca de Autores Cristianos, Sagrada Biblia, versión de Eloino Nacar y Alberto Colunga).

51 GIFRE, 13/I (Barcelona, 1993): 562; Dietaris de la Generalitat de Catalunya, V, Barcelona, Generalitat de Catalunya, 1999, págs. 991-992. 
como la excomunión subsiguiente de los tercios implicados, pero cuando a principios del año 1641 se fue a Barcelona para colaborar en el levantamiento del asedio de la capital lo hizo, según escribe, «para echar a los castellanos de la tierra», antes que para combatir a la herejía ${ }^{52}$. Sin embargo, no cabe duda de que los que daban más guerra - en todos los sentidos de la palabra - eran aquellos paisanos que por una u otra razón ni se pasaron por la notaría ni esperaban gran cosa de las instituciones de «la tierra», pero que, según parece, seguían con entusiasmo los dictados de la guerra santa. Por ello no resulta nada sorprendente la proliferación de partidas armadas que — según el testimonio, algo tardío, del ya citado Martí Viladamor - recorrían los caminos enarbolando el estandarte bíblico y providencialista de «Mihi vindicta» (Dt $32)^{53}$.

El estallido de la guerra, así como los inicios del dominio francés, cercenaron ese conato de milenarismo popular, aunque nada pudo impedir la implicación del estamento eclesiástico en el conflicto, de un lado u otro, ahora y más adelante. Desde luego, la guerra catalana de Separación nunca fue una guerra de religión. Sin embargo, en un tiempo en que la guerra (más) justa era todavía la guerra santa los eclesiásticos no pudieron quedar al margen de los acontecimientos. Su ascendiente entre la población hizo el resto.

\section{BIBLIOGRAFÍA}

Armstrong, Megan C., The Politics of Piety. Franciscan Preachers during the Wars of Religion, 1560-1600, Rochester (NY), University of Rochester Press, 2004.

Barrio Gozalo, Maximiliano, El clero en la España moderna, Córdoba, CSIC, 2010.

Basili de Rubí, Un segle de vida caputxina a Catalunya, 1564-1644, Barcelona, Caputxins de Sarrià, 1977.

Batllori, Miquel (S.I.), «Els jesuïtes i la Guerra de Catalunya (1640-1659)», en Batllori, Miquel (S.I.), Catalunya a l'època moderna. Recerques d'història cultural $i$ religiosa, Barcelona, Edicions 62, 1971.

Bercé, Yves-Marie, Révoltes et révolutions dans l'Europe moderna (XVIe-XVIIIe. siècles), París, PUF, 1980.

Busquets, Joan, «Bisbes espanyols i francesos a Catalunya durant la Guerra dels Segadors», en Albert Rossich y August Rafanell (eds.), El Barroc català, Barcelona, Quaderns Crema, 1989; 61-88.

52 PLADEVALL FONT y SIMON TARRÉS [eds.], 1986: 56-62.

53 MARTI VILADAMOR, Francisco, Cataluña en Francia, Castilla sin Cataluña y Francia contra Castilla: panegyrico glorioso al Christianíssimo Monarca Luis XIII el Justo, Barcelona, Ll. Deu, 1641, pág. 339. 
Busquets Dalmau, Joan, La Catalunya del Barroc vista des de Girona. La crònica de Jeroni de Real (1626-1683), Barcelona, Publicacions de l'Abadia de Montserrat, 1994.

Catalá Roca, Pere, El virrei Comte de Santa Coloma, Barcelona, Fundació Salvador Vives Casajuana, 1988.

Chaparro, Sandra: Providentia. El discurso político providencialista español de los siglos XVI y XVII, Madrid, Universidad Pontificia de Comillas, 2012.

Dentone, Catherine, Images de la francophobie en Espagne. L'écriture de la crise de 1635, Université de Paris-Sorbonne (Paris IV), 2000.

Domínguez Ortiz, Antonio, La sociedad española en el siglo XVII, vol. II, «El estamento eclesiástico», Madrid, 1970 (reedición facsímil, Granada, Universidad de Granada y CSIC, 1992).

Duran Sanpere, Agustí, «La defensa de la ciutat», en Duran Sanpere Agustí, Barcelona i la seva història, Barcelona, Curial, 1973, II: 109-123.

Elliott, John H., La rebelión de los catalanes (1598-1640), Madrid, Siglo XXI, 1977.

Ettinghausen, Henri, La Guerra dels Segadors a través de la prensa de l'època, Barcelona, Curial, 1993 (4 vols.).

Fontanella, Francesc, Panegíric a la mort de Pau Claris, edición de Montserrat Clarasó y Maria-Mercé Miró, Barcelona, Fundació Pere Coromines, 2008.

García Cárcel, Ricardo, Pau Claris: la revolta catalana, Barcelona, Dopesa, 1980.

Gifre, Pere, «Universitats, fiscalitat de guerra i privilegiats. A propòsit d'algunes universitats empordaneses durant la Guerra de Secessió», Pedralbes, 13/I (Barcelona, 1993), 561-572.

González Peiró, Ma . Rosa, «Los predicadores y la revuelta catalana de 1640. Estudio de dos sermones», en Actes del Primer Congrés d'Història Moderna de Catalunya, Barcelona, Universitat de Barcelona, 1984, II; 435-443.

Jover, José M., 1635. Historia de una polémica y semblanza de una generación, Madrid, CSIC, 1949 (reedición, Madrid, FEHM y CSIC, 2003).

Marques, João Francisco, A Parenética Portuguesa e a Restauraçao 1640-1668. A Revolta e a Mentalidade, Porto, Instituto Nacional de Investigação Científica, 1989 (2 vols.).

Martínez Ruiz, Enrique (dir.), El peso de la Iglesia. Cuatro siglos de Órdenes Religiosas en España, Madrid, Actas, 2004.

Neumann, Karsten, «La justificación «ante el mundo». Difusión y recepción de la propaganda catalana en Europa en 1640», Pedralbes, 18/II (Barcelona, 1998), 373-381.

Pladevall Font, Antoni y Simon Tarrés, Antoni [eds.], Guerra y vida pagesa a la Catalunya del segle XVII, Barcelona, Curial, 1986.

Pollmann, Judith., Catholic Identity and the Revolt of the Netherlands, 1520-1635, Oxford, Oxford University Press, 2011.

Puigvert, Joaquim M., «Guerra i Contrareforma a la Catalunya rural del segle XVII», en VV. AA., La revolució catalana de 1640, Barcelona, Crítica, 1991; 99-132. 
Puigvert, Joaquim M.: Església, territori i sociabilitat (s. XVII-XIX), Vich, Eumo, 2000.

Reglá, Joan, Els virreis de Catalunya, Barcelona, Teide, [1956].

Rourera, Lluís, Pau Duran (1582-1651) i el capitol i bisbat d'Urgell fins al Tractat dels Pirineus, [Bellaterra], Universitat Autònoma de Barcelona, 1987.

Saavedra Fajardo, Diego de, Empresas políticas [Munich, 1640; 2a . ed., Milán, 1642], ed. de F. Javier Díez de Revenga, Barcelona, Planeta, 1988.

Sales, Núria: Els segles de la decadència (segles XVI-XVIII), Barcelona, Edicions 62, 1989.

Sanabre, Josep, La acción de Francia en Cataluña en la pugna por la hegemonía de Europa, 1640-1659, Barcelona, Real Academia de Buenas Letras de Barcelona, 1956.

Serra, Eva (ed.), Escrits politics del segle XVII, t. II, «Secrets Públics, de Gaspar Sala, i altres textos», Barcelona - Vich, Institut Universitari d'Història Jaume Vicens Vives y Eumo editorial, 1995.

Serra, Eva, «Notes sobre l'esforç català a la campanya de Salses. Juliol 1639, Gener 1640», en Homenatge al doctor Sebastià García Martínez, Valencia, Generalitat Valenciana, 1988, II; 7-28.

Serra, Gisela., «La Vint-i-quatrena de Guerra. Mesures del Consell de Cent en començar la guerra dels Segadors», Barcelona Quaderns d'Història, 5 (Barcelona, 2001), 217-230.

Simon Tarrés, Antoni, Els orígens ideològics de la revolució catalana de 1640, Barcelona, Publicacions de l'Abadia de Montserrat, 1999.

Simon Tarrés, Antoni (ed.), Cròniques de la Guerra dels segadors, Barcelona, Fundació Pere Coromines, 2003a.

Simon Tarrés, Antoni: «Un «alboroto católico»: El factor religiós en la revolució catalana de 1640», Pedralbes, 23/II (Barcelona, 2003b), 123-146.

Simon Tarrés, Antoni, Pau Claris, líder d'una classe revolucionària, Barcelona, Publicacions de 1'Abadia de Montserrat, 2008.

Sobrequés, Jaume, (dir.), Història de Barcelona, Barcelona, Ajuntament de Barcelona y Enciclopèdia Catalana, 1992, IV.

Torres, Xavier (ed.), Escrits politics del segle XVII, t. I, «Noticia Universal de Cataluña, de Francesc Martí Viladamor», Barcelona - Vich, Institut Universitari d'Història Jaume Vicens Vives y Eumo editorial, 1995a.

Torres Sans, Xavier, La Vall de Torelló als segles XVI i XVII: una història de paraires $i$ bandolers, Vich, Eumo, 1995 b.

Torres, Xavier, La Guerra dels Segadors, Lérida, Pagès, 2006.

Torres Sans, Xavier, «Contra la décima eclesiàstica: en los albores de la revuelta catalana de 1640», en Jiménez Estrella, Antonio y Lozano Navarro, Julián J. (eds.), Actas de la XI Reunión Científica de la Fundación Española de Historia Moderna, Granada, Universidad de Granada, 2012a, II; 885-896. 
Torres, Xavier y Expósito, Ricard, «Els sermons de Sant Jordi de la Diputació de Catalunya: literatura i religió cívica», en Boadas, Sònia (ed.), Literatura en la Guerra de Treinta Años, Vigo, Academia del Hispanismo, 2012b; 129-150.

Villari, Rosario, La revuelta antiespañola en Nápoles. Los orígenes (1585-1647), Madrid, Alianza, 1979.

Zudaire, Eulogio, El Conde-Duque y Cataluña, Madrid, CSIC, 1964.

Recibido: 13/06/2013

Aceptado: 12/11/2013 